$4-2009$

\title{
Commitment, procedural fairness, and organizational citizenship behavior: a multifoci analysis
}

\author{
Vishnu Vinekar \\ Fairfield University, vvinekar@fairfield.edu \\ James J. Lavelle \\ University of Texas at Arlington \\ Joel Brockner \\ Columbia University
}

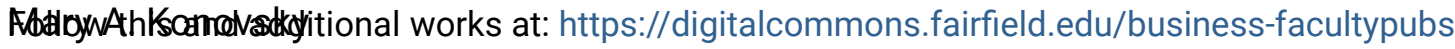

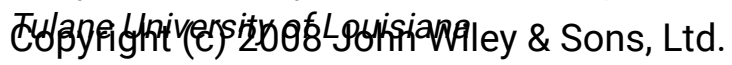

焻inista Roptiriedint of an article subsequently published in the Journal of Organizational

Belversiaty. of Texas at Arlington

Peer Reviewed

See next page for additional authors

\section{Repository Citation}

Vinekar, Vishnu; Lavelle, James J.; Brockner, Joel; Konovsky, Mary A.; Price, Kenneth H.; Henley, Amy B.; and Taneja, Aakash, "Commitment, procedural fairness, and organizational citizenship behavior: a multifoci analysis" (2009). Business Faculty Publications. 47.

https://digitalcommons.fairfield.edu/business-facultypubs/47

\section{Published Citation}

Lavelle, J.J., Brockner, J., Konovsky, M.A., Price, K.H., Henley, A.B., Taneja, A., Vinekar, V. (2009). Commitment, procedural fairness, and organizational citizenship behavior: a multifoci analysis. Journal of Organizational Behavior, 30 (3) 337-357.

This item has been accepted for inclusion in DigitalCommons@Fairfield by an authorized administrator of DigitalCommons@Fairfield. It is brought to you by DigitalCommons@Fairfield with permission from the rightsholder(s) and is protected by copyright and/or related rights. You are free to use this item in any way that is permitted by the copyright and related rights legislation that applies to your use. For other uses, you need to obtain permission from the rights-holder(s) directly, unless additional rights are indicated by a Creative Commons license in the record and/or on the work itself. For more information, please contact digitalcommons@fairfield.edu. 


\section{Authors}

Vishnu Vinekar, James J. Lavelle, Joel Brockner, Mary A. Konovsky, Kenneth H. Price, Amy B. Henley, and Aakash Taneja 
Running Head: A MULTIFOCI ANALYSIS

Commitment, Procedural Fairness, and Organizational Citizenship Behavior:

A Multifoci Analysis

JAMES J. LAVELLE*

University of Texas, Arlington

Department of Management

Arlington, Texas 76019

Tel: (817) 272-3854

Fax: (817) 272-3122

JOEL BROCKNER*

Columbia University

Uris Hall, Room 715

New York, NY 10025

Tel: (212) 854-4435

Fax: (212) 316-9355

MARY A. KONOVSKY

Tulane University

KENNETH H. PRICE

University of Texas, Arlington

AMY B. HENLEY

Kennesaw State University

AAKASH TANEJA

Richard Stockton College of New Jersey

VISHNU VINEKAR

Fairfield University

\section{In Press: Journal of Organizational Behavior}

Author Notes:

* The first two authors contributed equally to this manuscript.

We thank Linn Van Dyne for her valuable comments during the initial phases of this research.

Portions of this paper were presented to the 2005 Academy of Management Meeting, Honolulu, HI. 


\begin{abstract}
Research on commitment, procedural fairness, and organizational citizenship behavior (OCB) suggests that employees maintain distinct beliefs about, and direct behaviors towards, multiple targets in the workplace (e.g., the organization as a whole, their supervisor, and fellow workgroup members). The present studies were designed to test for "target similarity effects," in which the relationships between commitment, procedural fairness, and OCB were expected to be stronger when they referred to the same target than when they referred to different targets. As predicted, we found that: (1) the positive relationship between commitment and OCB, and (2) the mediating effect of commitment on the positive relationship between procedural fairness and OCB, was particularly likely to emerge when the constructs were in reference to the same target. Support for these target similarity effects was found among layoff survivors (Study 1) and student project teams (Study 2). Theoretical and practical implications are discussed, as are limitations of the studies and suggestions for future research.
\end{abstract}


Commitment, Procedural Fairness, and Organizational Citizenship Behavior:

\section{A Multifoci Analysis}

The construct of employee commitment is of considerable importance to both scholars (e.g., Mowday, Porter, \& Steers, 1982) and practitioners (e.g., O'Malley, 2000) alike. In the face of increased global competition organizations are more dependent upon the positive work attitudes and behaviors that typically emanate from employee commitment. For example, metaanalytic reviews show that organizational commitment is positively related to job performance, and that the commitment-performance relationship is more pronounced on measures of extra-role performance than on in-role performance (Mathieu \& Zajac, 1990; Riketta, 2002). The commitment literature distinguishes between different forms of commitment, such as affective, continuance, and normative (Allen \& Meyer, 1990). The focus of the present studies is on affective commitment, which is perhaps the most widely studied form of commitment, and is most similar to the way in which Mowday and colleagues (1982) conceptualized commitment in their groundbreaking work.

Given the positive consequences of a highly committed workforce, it is somewhat ironic that employees have been subjected to organizational downsizings and other changes in the psychological contract between employers and employees that often have the effect of reducing their commitment (Brockner, 1994). Consequently, there is an ongoing need to understand the causes, consequences, and processes associated with employee commitment.

Towards that end, an important conceptual development in the commitment literature is the multifoci perspective (e.g., Becker, 1992; Bishop \& Scott, 2000; Coyle-Shapiro \& Morrow, 2006; Liden, Wayne, Kraimer, \& Sparrowe, 2003; Reichers, 1985). This framework suggests that employees may maintain meaningfully distinct levels of affective commitment (i.e., 
attachment based on identification or affiliation; e.g., O'Reilly \& Chatman, 1986) towards various entities in the workplace, such as the organization, top management, their supervisor, and their workgroup. The multifoci perspective also has emerged in the literature on organizational justice (e.g., Blader \& Tyler, 2003; Cropanzano, Byrne, Bobocel, \& Rupp, 2001; Rupp \& Cropanzano, 2002), in which, for example, employees may hold meaningfully different beliefs about the fairness with which various decision-making agents go about planning or implementing decisions.

The multifoci approach also has gained traction in the literature on organizational citizenship behavior (OCB; e.g., Lepine, Erez, \& Johnson, 2002; Skarlicki \& Latham, 1996; Williams \& Anderson, 1991). For example, certain citizenship behaviors may be directed towards the organization (OCBO), such as attending voluntary meetings or events pertaining to the organization, whereas others may be directed towards specific individuals within the organization (OCBI). Moreover, the "I" in OCBI may differ, such that sometimes people may do extra work for their supervisor whereas on other occasions they may volunteer to help members of their workgroups. Whereas it is theoretically possible for certain citizenship behaviors to influence multiple targets (for example, helping co-workers may have an indirectly positive effect on the organization as a whole), the key to the multifoci perspective is that people meaningfully distinguish between targets (hence, in the above example the fact that helping coworkers also happens to have a positive effect on the organization as a whole is not a driving force for the focal actor exhibiting the citizenship behavior).

Previous research has employed a multifoci approach to test hypotheses associated with two of the three constructs of employee commitment, procedural fairness, and organizational citizenship behavior (OCB). For example, Becker and Kernan (2003) examined relationships between 
employee commitment and OCB, whereas Rupp and Cropanzano (2002) studied relationships between procedural fairness and OCB. These studies generally provided evidence of a "target similarity effect," in which the relationship between constructs tended to be stronger when the constructs referred to the same target than when they referred to different targets.

The target similarity effect is noteworthy on both theoretical and practical grounds. At the theoretical level, it provides an important extension to previously established relationships, such as between procedural fairness and commitment (e.g., Brockner, 1994), between procedural fairness and OCB (e.g., Moorman, 1991), and between commitment and OCB (e.g., Moorman, Niehoff, \& Organ, 1993), in that these relationships are stronger when the constructs refer to the same target. At the practical level, managers sometimes may be more concerned with heightening certain types of outcomes (e.g., OCBO) rather than others (e.g., OCBI). If so, then it is important to delineate those factors that will be particularly likely to have an effect on the type of outcome that they are seeking to foster. For example, if managers are concerned with how to heighten OCBO, then the target similarity effect suggests that they should focus their efforts on employees' perceptions of the organization's procedural fairness, rather than on, say, the procedural fairness exhibited by members of their workgroup.

Given the significance of the target similarity effect, it is important that we deepen our understanding of it. The present studies are designed to do so, in several respects. First, we provide a theoretical justification for the target similarity effect, by grounding it in the broader social psychological literature on the relationship between people's beliefs/attitudes and their behaviors. Whereas previous studies have taken a multifoci approach to the three constructs of procedural fairness, commitment, and organizational citizenship behavior "two at a time" within a given study, the present studies apply the multifoci approach to all three constructs simultaneously. In so doing, 
the second and third contributions of the present studies (stated below) show how further analyses of the target similarity effect may enable us to contribute to several matters of importance in the literature on organizational citizenship behavior.

Second, whereas previous research already has established that procedural fairness is positively related to OCB (e.g., Rupp \& Cropanzano, 2002), the present studies evaluate an heretofore unexamined mediator of the relationship between procedural fairness and OCB: commitment. The focus on multifoci commitment contributes to our understanding of why perceptions of fairness associated with particular sources of justice may affect citizenship behaviors directed toward those particular targets. We investigate whether organizational commitment mediates the relationship between the organization's procedural fairness and OCBO (in Study 1), and whether commitment to the workgroup mediates the relationship between the workgroup's procedural fairness and OCBI (in Study 2). Third, whereas previous research has shown that OCB varies along numerous dimensions, including the target towards which it is directed, an earlier review was unable to delineate factors that are differentially predictive of the OCB that employees direct towards different targets (LePine et al., 2002). The target similarity effect (which was not considered in the LePine et al. review) may help us to differentially predict the degree of OCB that employees direct towards various targets.

\section{THEORETICAL GROUNDING}

The conceptual foundation for the target similarity effect is provided by longstanding theory and research on attitude-behavior relationships (e.g., Fishbein \& Ajzen, 1975). An intriguing problem that plagued attitude researchers for years was that attitudes often were found to be weakly or not at all predictive of behaviors, even though the two appeared to be conceptually related to one another. In response to this disappointing empirical yield, attitude 
researchers subsequently posited that the strength of the relationship between attitudes and behaviors depends upon the extent to which the constructs are similar in their scope. In most studies (i.e., the ones yielding little or no relationship between attitudes and behaviors), the two were not similar in their scope (Ajzen \& Fishbein, 1977). That is, researchers generally tried to predict specific behaviors on the basis of global attitudes.

Further research showed that global attitudes may predict behaviors, but that the behaviors needed to be global in scope, that is, the behaviors needed to reflect people's actions across a range of situations relevant to the attitude, rather than their action in a specific situation only (Weigel \& Newman, 1976). Moreover, specific behaviors could be predicted, but the attitudes needed to be specific in scope, that is, the attitude needed to correspond to people's behavior in the particular instance, rather than reflect their attitudes in general. Fishbein and Ajzen (1975; Ajzen \& Fishbein, 1980) formalized the importance of target similarity in their theory of reasoned action. According to the theory, maximal prediction of behavior by attitude occurs when the attitude corresponds to behavior in terms of action, context, time, and target. Thus, in the context of the present research, behavior towards co-workers (such as OCBI, in which the "I" refers to co-workers) is more likely to be predicted by attitudes towards coworkers (such as commitment to co-workers) than by attitudes towards the organization (such as organizational commitment).

As the preceding example suggests, one basis of determining an attitude's specificity is its target (Fishbein \& Ajzen, 1975). Attitudes directed towards a particular target are more specific than are attitudes directed towards multiple targets or towards unspecified targets. Thus, when the behavior refers to a specific target, and when the attitude and behavior have the same target, the attitude is more relevant to the behavior and hence is more likely to be predictive of the 
behavior. In sum, the target similarity effects investigated in the present research are grounded in attitude theory and research, which posit that attitudes are especially likely to predict behavior when the two constructs are similar in their scope, for example, when they refer to the same target. We test for two types of target similarity effects in the present studies: (1) employee commitment as a predictor of $\mathrm{OCB}$, and (2) employee commitment as a mediator of the relationship between procedural fairness and OCB.

\section{Employee Commitment as a Predictor of OCB}

Organ (1988) defined organizational citizenship behavior as discretionary, voluntary behaviors that are neither part of an employee's role requirements nor formally rewarded by the organization. Researchers have suggested that OCB contributes indirectly to organizational effectiveness by enhancing the "social and psychological context that supports task performance" (Organ 1997, p. 1). Moreover, OCB is likely to be increasingly important during times of significant change, because organizations cannot consistently anticipate or specify all of the employee behaviors that will contribute to organizational effectiveness under conditions of uncertainty (Van Dyne \& LePine, 1998).

Given the importance of the consequences of OCB, researchers have tried to identify its antecedents or predictors (see LePine et al., 2002). A basic tenet of prior research and theory in the OCB literature is that citizenship behaviors are motivated by positive job attitudes such as commitment (Konovsky \& Pugh, 1994; Organ \& Ryan, 1995). Indeed, as Mowday et al. (1982) implied in their seminal work, OCB is a behavioral expression or perhaps consequence of the underlying attitude of organizational commitment.

Researchers also have suggested that commitment can be viewed as an attitudinal indicator of the extent to which an employee perceives him or herself to be in a high-quality social exchange 
relationship with the organization (Cropanzano \& Mitchell, 2005). In contrast to economic exchange which refers to a quid pro quo exchange of tangible resources with a short-term focus, social exchange relationships are often described as subjective, relationship-oriented contracts between employers and employees characterized by a mutual exchange of socio-emotional benefits (Blau, 1964; Van Dyne, Graham, \& Dienesch, 1994). For example, in exchange for support from the organization, an employee may demonstrate commitment to the organization (Eisenberger, Huntington, Hutchison, \& Sowa, 1986; Rhoades, Eisenberger, \& Armeli, 2001). Researchers argue that high-quality social exchange relationships (as indicated by commitment, for example) are likely to prompt employees to engage in citizenship because employees are likely to feel a relational obligation to engage in behaviors that have positive consequences for their relationship partners (Cropanzano \& Rupp, in press; Lavelle, Rupp, \& Brockner, in press; Van Dyne et al., 1994).

One matter of considerable theoretical significance is whether OCBO (such as participating in voluntary meetings or events regarding the organization) and OCBI (such as helping co-workers with heavy workloads) are elicited by different factors (e.g., Williams \& Anderson, 1991). OCB researchers have speculated that there are a variety of ways in which employees may engage in organizational citizenship behaviors. Empirical research is needed, however, to determine whether meaningful differences in the nature of OCB exist. One way to test for such differences is to evaluate whether the various forms of OCB are elicited by different factors.

Whereas the LePine et al. (2002) meta-analysis did not unearth factors that were differentially predictive of OCBO and OCBI, recent studies taking a multifoci approach have been somewhat more encouraging in their ability to predict OCBO and OCBI differentially (Becker \& Kernan, 2003; Rupp \& Cropanzano, 2002). The present research further evaluated whether a multifoci perspective could aid in the differential prediction of OCBO and OCBI. In both the 
Becker and Kernan (2003) and Rupp and Cropanzano (2002) studies, the "I" in OCBI referred to participants' supervisors. However, with the flattening of organizational hierarchies and the advent of teams in the workplace, it is increasingly important to examine how employees' attitudes and behaviors may be affected by their co-workers. Hence, the "I" in the present studies referred to the people in participants' workgroups. In Study 1, employees indicated their level of commitment to the organization as well as to the members of their workgroup. Moreover, measures of OCBO and OCBI were collected in Study 1.

Hypothesis 1a: Employees' commitment to the organization will be more likely than their commitment to their fellow workgroup members to be positively related to their OCBO. Hypothesis 1b: Employees' commitment to their fellow workgroup members will be more likely than their commitment to the organization to be positively related to their OCBI.

\section{Employee Commitment as a Mediator}

Just as the multifoci perspective may provide further insight into the differential prediction of OCBO and OCBI, it may shed light on a related matter that also has received a great deal of conceptual and empirical scrutiny: how to explain the relationship between procedural fairness and OCBO. Several recent meta-analyses have shown employees' perceptions of organizational justice (distributive, procedural, and interactional) to be positively related to their tendencies to engage in OCB (Cohen-Charash \& Spector, 2001; Colquitt, Conlon, Wesson, Porter, \& Ng, 2001; LePine et al., 2002; Viswesvaran \& Ones, 2002). Though not explicitly labeled as such, procedural fairness typically refers to aspects of the organization's formal decision-making methods (Folger \& Cropanzano, 1998). Consistent with the target similarity effect, Cohen-Charash and Spector found that procedural fairness was much more strongly related to OCBO than it was to OCB directed towards one's supervisor. 
We posit that commitment (in particular, organizational commitment) will mediate the relationship between procedural fairness (in particular, the organization's procedural fairness) and OCB (in particular, OCBO). Whereas Hypotheses 1a and $1 \mathrm{~b}$ already have suggested that commitment is likely to be predictive of OCB (particularly when the constructs were in reference to the same target rather than different targets), the mediational hypothesis requires us to account for the hypothesized relationship between procedural fairness and organizational commitment. Relational models of organizational justice (e.g., Tyler \& Lind, 1992) have posited that people prefer to be treated with high procedural fairness because fair procedures symbolize that they are respected and valued by the party enacting the procedures. Put differently, high procedural fairness communicates to employees that the organization supports them and indicates they have more of a social exchange relationship with their employer. In this mutual exchange, employees may reciprocate being treated with high procedural fairness by showing positive attitudes such as high organizational commitment (Cropanzano \& Rupp, in press).

The relational model of justice has delineated a second mechanism (other than reciprocity) through which procedural fairness may be positively related to organizational commitment. High procedural fairness enacted by organizational authorities motivates employees to make the organization part of their social identity. After all, high procedural fairness is morally admirable, and most people would like to see themselves as morally admirable. One way that they can achieve this valued self-conception is by psychologically aligning themselves with the organization. By defining themselves based upon their organizational membership, employees may attain valued self-conceptions to the extent that the organization is morally admirable, e.g., if organizational authorities behave with high procedural 
fairness. Of course, psychological alignment with an organization is part and parcel of being committed to that organization (Mowday et al., 1982).

In summary, the reasoning set forth above as well as empirical evidence (e.g., Brockner, 1994) provide support for the notion that an organization's procedural fairness will be positively related to employees' organizational commitment. Moreover, implicit in Hypothesis 1a is the notion that organizational commitment is likely to be positively associated with OCBO. If an organization's procedural fairness leads to organizational commitment, and if organizational commitment leads to $\mathrm{OCB}$, then it stands to reason that organizational commitment will mediate the relationship between an organization's procedural fairness and employees' OCBO.

Hypothesis 2a: The positive relationship between organizational procedural fairness and OCBO will be mediated by employees' organizational commitment.

Furthermore, the target similarity effect emanating from the multifoci perspective suggests the following related prediction:

Hypothesis $2 b$ : The positive relationship between organizational procedural fairness and OCBO is more likely to be mediated by employee commitment directed towards the organization than by employee commitment directed towards the workgroup.

\section{The Context for Study 1: Survivors' Reactions to Organizational Layoffs}

All hypotheses in Study 1 were examined on a sample of employees who had survived an organizational downsizing. This point is noteworthy for two reasons. First, the downsizing context enabled us to contribute to theory and research on the determinants of survivors' reactions to job layoffs (e.g., Brockner, 1994). Organizations downsize their workforces in the hopes of improving their performance. However, the effect of layoffs on organizational performance has been shown to be quite variable (e.g., Cascio, 1993). One explanation of these 
mixed findings is that the employees who remain following a downsizing ("layoff survivors") respond in very different ways, some showing reduced productivity and morale, others showing improved productivity and morale, and still others showing no effects at all. Prior research has sought to identify the factors that may account for the variance in survivors' reactions. One such factor is organizational justice. The more survivors believe that the layoffs were fair (distributively, procedurally, and interactionally), the better they tend to respond (Brockner, 1994).

In none of the previous studies of survivors' reactions, however, did OCB serve as the dependent variable. Thus, Study 1 affords an opportunity to extend previous fairness effects shown by layoff survivors to a new dependent variable. Furthermore, whereas how much employees engage in OCB is generally likely to have important organizational consequences, this may be particularly true following a downsizing, when the very survival of the organization may well depend on how much employees are willing to "go the extra nine yards."

Second, the layoff survivor context made it less feasible to test for the mediating effect of employees' commitment to the workgroup on the relationship between workgroup procedural fairness and OCBI. After all, the downsizing was an event initiated by the organization rather than by one's co-workers. As a result, the workgroup's procedural fairness (defined as the justness or propriety of the formal methods used by the workgroup to make decisions or allocate resources) was not likely to be a relevant construct. This shortcoming was redressed, however, in Study 2, which was conducted in a context in which the workgroup's procedural fairness was a relevant construct. Thus, Study 2 evaluated whether commitment to the workgroup mediated the relationship between the workgroup's procedural fairness and people's OCBI. ${ }^{1}$ 
Study 1

Method

\section{Procedures}

The data for Study 1 came from a larger study of employees of a medical clinic in the United States that had laid off a little over 10 percent of its 450 employees. A survey packet was sent to all 400 layoff survivors through the organization's internal mail system approximately two weeks after the last day of employment for the layoff victims. Layoff victims had been notified approximately four weeks prior to their final day of employment. The packet contained a letter signed by the clinic's Chief Executive Officer and one of the authors requesting participation, a business-reply envelope addressed to the university address of the same author, and the survey instrument. Respondents were guaranteed confidentiality, and anonymity was achieved by specifically instructing participants not to write their names anywhere on the survey.

\section{Respondents}

Of the 400 surveys distributed, 106 usable ones were returned within two weeks for an overall response rate of 27 percent. The respondents were primarily female (91.4\%) with an average organizational tenure of 4.73 years. Their average age was 38.8 years. Approximately 80 percent of the respondents held an associate degree or higher educational degree. Whereas the response rate was typical for organizational surveys administered using mail-in procedures (Grandey, 2003), the relatively low return rate is a potential limitation. As a test of response bias, we compared the demographics of our respondents along the dimensions of age, gender, and tenure with that of the overall organization, based on information provided to us by management. Somewhat reassuringly, no significant differences were found (the members of the organization were approximately $90 \%$ female with an average age and organizational tenure of approximately 
39.5 years and 5 years, respectively). Whereas we did not collect information on participants' race/ethnicity, most organization members (approximately 85\%) were Caucasian. Survey Design Features

Due to constraints imposed by the participating organization, we used self-reports to measure all of the variables reported in this study. As such, we took a number of steps in the survey design to minimize the potential impact of common method variance (Podsakoff, MacKenzie, Lee, \& Podsakoff, 2003). For example, we separated the predictor and criterion measures on the survey, and we placed objective demographic questions in between. We also protected the anonymity of the respondents, in the hopes of making participants less likely to respond in a socially desirable, acquiescent, or lenient manner. Furthermore, the key items were embedded in a longer survey that included other measures not relevant to the purpose of the present research.

\section{Measures}

Types of Citizenship. McNeely and Meglino (1994) criticized prior measures of OCBI and OCBO (e.g., Smith, Organ, \& Near, 1983; Williams \& Anderson, 1991) for containing items that do not clearly differentiate citizenship behaviors according to the intended beneficiary. We kept this concern in mind when selecting our measures. To assess citizenship toward co-workers, we selected Podsakoff, MacKenzie, Moorman, and Fetter's (1990) widely used altruism subscale of OCB, because the items in that measure tap behaviors intended to help individuals who are members of one's workgroup.

Two of the five items in the Podsakoff et al. (1990) measure were discarded. One referred to orienting new co-workers, which was not appropriate to the layoff context (in which people were being let go rather than new people coming in), and the other was more of an attitudinal measure (readiness to help others) than a behavioral measure. Thus, the following three items 
were used to measure OCBI: "It is characteristic of me to help others who have heavy workloads," "It is characteristic of me to help others who have been absent," and "I characteristically give my time to help others with work problems."

To measure citizenship toward the organization we selected Morrison's (1994) involvement subscale of OCB, because it contains items in which the organization is clearly the intended beneficiary of the behavior. Although Williams and Anderson's (1991) measure also has been used to assess OCBO, Lee and Allen (2002) raised concerns about that measure because it refers to behaviors that appear to overlap with measures of workplace deviance behavior (e.g., Bennett \& Robinson, 2000). Morrison's (1994) scale does not contain any obvious overlap with workplace deviance behavior, suggesting that it more exclusively taps behaviors intended to benefit the organization itself.

One item in Morrison's (1994) three-item scale refers to organizing departmental get togethers. Given the potential ambiguity concerning the true beneficiary of this behavior, (i.e., the department, the workgroup, or the organization itself) we excluded this item. Consequently, the following two items from the Morrison (1994) subscale were used to measure OCBO: "I attend functions that are not required but help the company image," and "I attend and participate in voluntary meetings regarding the organization." It is also worth mentioning that the items used to measure both types of citizenship in Study 1 were rated as among the most likely to be judged by employees to reflect extra-role rather than in-role behavior (Morrison, 1994).

Given the salience of the downsizing event, we wished to examine employees' perceptions of how the downsizing (and the procedural fairness with which it was handled) affected their citizenship behavior. Consequently, participants were asked to report the extent to which their citizenship behavior had changed after the layoff relative to before the layoff. This method of 
measurement has been used in previous research on survivors' responses to layoffs (e.g., Brockner, Tyler, \& Cooper-Schneider, 1992). As in those prior studies, respondents were instructed to indicate their opinion "now in comparison to how you felt one month prior to first hearing that there would be layoffs." To assess the extent to which survivors' coworker-directed and organizationallydirected citizenship had changed since the layoff, the endpoints for each item were "applied to me more before the layoff than now" (1) and "applies to me more now than before the layoff" (11). The middle point of the scale was "applies to me the same" (6). Coefficient alpha for these and all scales used in Study 1 were acceptable (greater than .70) and are reported in Table 1.

Organizational Procedural Fairness. Measures of procedural fairness have taken several forms in previous research. Sometimes, participants have evaluated specific procedural elements that have been shown to influence fairness judgments, such as the consistency or the criteria with which decisions are made (Leventhal, Karuza, \& Fry, 1980). On other occasions, participants have been asked to reflect on the procedures as a whole, and to rate their fairness (e.g., Lind \& Tyler, 1988). Study 1 consisted primarily of the former type of items, whereas, as described later, Study 2 consisted of the latter type of items. The measure of procedural fairness used in Study 1 pertained to the organization's formal decision-making methods in implementing the downsizing. Three of the four items used in the current study were taken from Greenberg (1993) and were re-worded slightly to be appropriate to the layoff context. These items included: "The method used to determine who would be laid off was consistent and unbiased," "The method used to determine who would be laid off was fair," and "Proper rules and procedures were used to determine who would be laid off." The fourth item was previously used by Brockner et al. (1992) to measure layoff survivors' perceptions of the fairness of the criteria used to determine who would be laid-off. The item was: "The criteria used to determine who would be laid off were fair." Endpoints for the seven-point 
organizational procedural fairness scale were "Strongly disagree" (1) and "Strongly agree" (7).

Targets of Commitment. We measured identification-based affective commitment to the organization and identification-based affective commitment to the workgroup using five-item scales developed by Becker (1992). The following items were used to measure commitment to the organization: (1) "When someone criticizes this organization it feels like a personal insult," (2) "When I talk about this organization, I usually say 'we' rather than 'they,"' (3) "This organization's successes are my successes," (4) "When someone praises this organization it feels like a personal compliment," and (5) "I feel a sense of ownership for this organization." Consistent with Becker (1992) we used the same five items noted above to measure commitment to the workgroup by replacing each organizational target with a workgroup target. For example, one of the items in the workgroup commitment scale was, "When someone criticizes my workgroup it feels like a personal insult." As in the case of OCB, we wished to examine employees' perceptions of how the downsizing (and the procedural fairness with which it was handled) affected their commitment. Hence, to assess the extent to which organizational commitment and workgroup commitment had changed since the layoff, the endpoints for each item were "applied to me more before the layoff than now" (1) and "applies to me more now than before the layoff" (11). The middle point of the scale was "applies to me the same" (6). Strictly speaking, then, Hypotheses 1a and $1 \mathrm{~b}$ tested for target similarity effects in evaluating whether layoff survivors' perceived change in commitment was related to perceived change in their citizenship behavior, relative to before the layoffs. Hypotheses $2 \mathrm{a}$ and $2 \mathrm{~b}$ examined whether perceived change in commitment mediated the relationship between perceptions of the procedural fairness of layoff decision-making and employees' perceived change in their citizenship behaviors.

Results and Discussion 


\section{Convergent and Discriminant Validity Analysis}

To evaluate the convergent and discriminant validity of our measures and further address potential concerns associated with common method variance, we conducted a confirmatory factor analysis (CFA). Following the approach recommended by Andersen and Gerbing (1988), convergent validity can be established when the path loading from an item to its latent construct is significant and discriminant validity can be established by comparing the fit (using chi-square difference tests) of the unconstrained measurement model to alternative models in which two latent constructs are constrained at a time by setting their correlations equal to one.

First, using the maximum likelihood method we estimated a five-factor measurement model including all items measuring organizational procedural fairness, organizational commitment, workgroup commitment, and organizationally- and individually-directed forms of citizenship behavior. Fit statistics were within generally accepted ranges indicating that our model provided a good fit to the data $\left(\mathrm{X}^{2}(143)=260, p<.0001 ; \mathrm{CFI}=.919 ; \mathrm{IFI}=.922 ; \mathrm{RMSEA}=.088\right)$. All individual path loadings from an item to its specified latent construct were significant, providing evidence of convergent validity. Next, following the procedure outlined above, we compared our measurement model to each of the ten possible alternative models using chi-square difference tests. In each case, the chi-square difference test was significant, $p<.0001$, indicating that our measurement model fit the data better than any of these alternative models. Consequently, CFA results support the convergent and discriminant validity of the five constructs.

The means, standard deviations, scale reliabilities, and correlations among the study variables are presented in Table 1. Tests of Hypotheses

Hypotheses $1 a$ and $1 b$. Multiple regression analyses were used to test Hypotheses $1 \mathrm{a}$ and $1 \mathrm{~b}$ 
(see Table 2). OCBO and OCBI were regressed separately on organizational commitment, workgroup commitment, and organizational procedural fairness. We predicted that employees' commitment to the organization would be more predictive of their OCBO than would their workgroup commitment (Hypothesis 1a). Moreover, we expected that employees' commitment to their fellow workgroup members would be more predictive of their OCBI than would their organizational commitment (Hypothesis 1b). The results presented in Table 2 are consistent with both predictions, showing that: (1) organizational commitment was significantly related to OCBO whereas workgroup commitment was not, and (2) workgroup commitment was significantly related to OCBI, whereas organizational commitment was not.

Moreover, the relationship between organizational commitment and OCBO (partialling out the effects of workgroup commitment and procedural fairness) was significantly greater than the relationship between workgroup commitment and OCBO (partialling out the effects of organizational commitment and procedural fairness; $r \mathrm{~s}=.43$ and .16 , respectively, $z=2.14, p<.02$, one-tailed). In addition, the relationship between workgroup commitment and OCBI (partialling out the effects of organizational commitment and procedural fairness) was significantly greater than the relationship between organizational commitment and OCBI (partialling out the effects of workgroup commitment and procedural fairness; $r \mathrm{~s}=.30$ and .07 , respectively, $z=1.75, p<.04$, one-tailed).

Hypotheses $2 a$ and $2 b$. To evaluate Hypothesis $2 \mathrm{a}$ we drew on the principles set forth by Baron and Kenny (1986) for testing mediation. From Table 1 it can be seen that: (1) organizational procedural fairness was significantly related to the dependent variable of OCBO, (2) organizational procedural fairness was significantly related to the hypothesized mediating variable of organizational commitment, and (3) organizational commitment was significantly related to OCBO. 
Baron and Kenny further suggest that evidence of mediation is present when the relationship between the independent variable and the dependent variable is lessened to a significant extent when the presumed mediating variable is controlled, and furthermore, that the relationship between the presumed mediator and the dependent variable remains significant. In fact, when OCBO was regressed simultaneously on organizational procedural fairness and organizational commitment, the effect of organizational procedural fairness became trivial $(\beta=.10, p>.20)$ whereas the effect of organizational commitment remained highly significant $(\beta=.49, p<.001)$. Moreover, the results of a Sobel test showed that the relationship between organizational procedural fairness and OCBO was significantly lower when organizational commitment was controlled, relative to when it was not, $z=$ $2.82, p<.01$. In sum, organizational commitment fully mediated the relationship between organizational procedural fairness and OCBO.

In contrast, commitment to the workgroup did not even partially mediate the relationship between organizational procedural fairness and OCBO. For one thing, organizational procedural fairness was unrelated to commitment to the workgroup, as can be seen in Table 1. Moreover, the relationship between organizational procedural fairness and OCBO was virtually identical, regardless of whether commitment to the workgroup was not controlled for $(\beta=.26, p=.01)$, or was controlled for $(\beta=.23, p=.02)$. The above analyses provide support for both $\mathrm{H} 2 \mathrm{a}$ and $\mathrm{H} 2 \mathrm{~b}$.

\section{Limitation}

Whereas the dependent measure of OCB represents an important extension to the literature on layoff survivors, it was measured with self-reports in Study 1. This raises the question of whether similar results would emerge if other measures of OCB had been employed, such as supervisors' or co-workers' ratings of the participants' OCB. In fact, Riketta's (2002) 
recent meta-analysis of the relationship between organizational commitment and job performance provides evidence that is particularly relevant to this issue.

From the published version of Riketta's (2002) meta-analysis, it is impossible to discern the subset of studies in which the job performance measure consisted of extra-role performance (OCB). Because those studies are particularly germane to the present research, we contacted Riketta to see if he would perform a meta-analysis based only on those studies in which the job performance measure was extra-role, i.e., consisted of OCB. In fact, Riketta (personal communication) found that among those studies in which the performance measure consisted of OCB, the relationship between organizational commitment and OCB did not vary to a significant extent as a function of whether the OCB measure consisted of self-reports (mean corrected correlation $=.31)$ versus supervisors' reports $($ mean corrected correlation $=.24) ; \mathrm{z}=1.41, p>$ .10. This finding strongly suggests that the results of Study 1 (for example, the target similarity effects that emerged in support of Hypotheses 1a and 1b) were unlikely to be an artifact of the use of self-reports to measure OCB.

\section{Study 2}

Study 2 was designed to build on the promising results of Study 1 in several ways. Whereas Hypotheses $1 \mathrm{a}$ and $1 \mathrm{~b}$ allowed for a complete test of the target similarity effect by having matching targets for each of the commitment and OCB variables, the measures in Study 1 pertaining to Hypotheses $2 \mathrm{a}$ and $2 \mathrm{~b}$ only allowed us to examine the extent to which the commitment variables mediated the relationship between organizational procedural fairness and citizenship directed towards the organization. More specifically, the test of Hypothesis 2a showed that organizational commitment mediated the relationship between two variables with an organizational target (organizational procedural fairness and organizationally-directed citizenship). However, what was 
not examined in Study 1 but is suggested by the target similarity framework is that employees' commitment to their workgroups will mediate the relationship between the workgroup's procedural fairness and citizenship directed towards these co-workers. Accordingly, this hypothesis was tested in Study 2.

It is also worth noting that relatively few, if any, studies have examined the effects of workgroup procedural fairness on employees' attitudes or behaviors, particularly when the workgroup is conceptualized as the agent of the procedure. Instead, the vast majority of organizational justice studies have looked at the effects of either the perceived fairness of one's manager, or the perceived fairness of the organization as a whole (i.e., entities perceived to have greater formal authority). Workgroups however, are an increasingly important, yet under examined source of procedural justice (Lavelle et al., in press). Hence, Study 2, in which the workgroup was the target for all constructs, is one of the few to focus on the consequences of workgroup procedural fairness.

Study 2 also was designed to provide some methodological enhancements over its predecessor. As in Study 1, the measures of procedural fairness and commitment consisted of participants' self-reports. Unlike in Study 1, however, the measure of OCBI in Study 2 consisted of the judgments of fellow workgroup members concerning how much each participant engaged in citizenship behavior toward these co-workers. This enabled us to evaluate whether the relationships between OCBI and each of workgroup procedural fairness and workgroup commitment generalize to a situation in which the measure of citizenship comes from a source other than participants' themselves. Given that the procedural fairness and commitment measures were based on participants' self-reports, the fact that the measure of citizenship behavior toward co-workers consisted of peer ratings also reduced the likelihood of common methods as an alternative 
explanation of the results of Study 2.

All participants in Study 2 worked in student project groups, similar to self-managing teams, in which the team members themselves (as opposed to supervisors or managers) are primarily accountable for making a number of decisions (e.g., task assignments, scheduling, and workloads) pertaining to task completion. After working together, typically over a twelve-week period, group members rated the fairness of their group's decision-making procedures, they rated their commitment to the group, and they rated one another's tendencies to engage in citizenship behavior. Hypothesis 3: The positive relationship between the perceived fairness of the workgroup's decision-making procedures and OCBI will be mediated by participants' commitment to the workgroup.

Method

\section{Setting, Participants, and Procedure}

The data for Study 2 were drawn from project teams at a large university in the United States. Students enrolled in management, marketing, and information systems courses at both the undergraduate and graduate levels worked together in teams to complete a research project assigned and graded by their respective instructors as part of their regular course requirements. These projects required students to work together inside and outside of class throughout the semester, typically culminating with an oral presentation and written report. Team projects typically lasted for 10-14 weeks of the 16-week semester; none of the authors taught any of these courses.

Study participation was optional and involved the completion of a survey. To provide an incentive to participate, some instructors offered extra-credit; all those completing surveys were entered into a drawing with an opportunity to win gift certificates for use at a local 
restaurant. The survey was administered shortly after students had completed their projects but before they had received their grades. Completed surveys were received from 635 of the 794 students enrolled in the courses, for a response rate of $80 \%$. Hence, the likelihood of a selfselection bias was considerably lower in Study 2 than in Study 1. Participants worked in teams with a median size of five team members, with virtually all of them $(96 \%)$ having team sizes ranging from three to seven members. Approximately $17 \%$ of participants were graduate students, $52 \%$ were male, $80 \%$ worked at least part-time, and their average age was 26 (SD = 6.5). Fifty-three percent of the participants were Caucasian, $15 \%$ were Asian, $10 \%$ were African-American, 14\% were Hispanic, and 8\% described themselves as having "other" ethnicities.

Consistent with our attempt to examine how individuals' perceptions of fairness and levels of commitment were related to their citizenship behaviors, tests of hypotheses were conducted at the individual level of analysis. In addition, hypothesis testing was based only on those participants who were rated by two or more of their peers, in an attempt to increase the accuracy of the citizenship measure. This resulted in a useable sample of 594 participants (approximately $94 \%$ of those completing the survey). When single-rater assessments of citizenship behavior were also included in the data analysis, the results were highly similar to, and the conclusions drawn did not change from, those reported here using only multiple-rater assessments citizenship.

\section{Measures}

Procedural Fairness of the Workgroup. A three-item scale was used to measure individuals' perceptions of the fairness of the procedures used by their group to make important decisions regarding their project (e.g., decisions pertaining to project content, scheduling, 
deliverables, and goals as well as to the allocation of roles, responsibilities, and workload among group members). Based on work by Lind and Tyler (1988), the items asked individuals to assess the extent to which their group's decision-making procedures were: unfair (1) to fair (7), unjust (1) to just (7), and improper (1) to proper (7). Coefficient alphas for this and all multi-item scales included in Study 2 were acceptable and are reported in Table 3.

Commitment to the Workgroup. We measured individuals' commitment to their workgroup with three items based on Allen and Meyer's (1990) affective organizational commitment scale (to fit the workgroup context, we replaced reference to the organization with reference to the team). Example items include: "I feel a part of this team" and "I feel a sense of belongingness to this team.” Endpoints for the seven-point Likert-type scale were "Strongly disagree" (1) and "Strongly agree" (7).

$O C B I$. Peer ratings were used to measure the extent to which individual team members engaged in organizational citizenship behavior beneficial to the workgroup. Based on prior research, (e.g., Podsakoff et al., 1990) participants rated how characteristic $(1=$ very uncharacteristic and $7=$ very characteristic) it was for each one of their group members "to volunteer to help out, provide assistance, and lend a helping hand when someone needs help." To make these peer ratings, participants were given a team roster listing the name of each person in their workgroup as part of the survey materials. For these multi-rater assessments of an individual's tendency to engage in this type of citizenship, the level of inter-rater agreement was acceptable (median $\operatorname{Rwg}_{(\mathrm{i})}=.77$ ). Consequently, we averaged the citizenship ratings across raters.

\section{Results}

The means, standard deviations, scale reliabilities, and correlations among the Study 2 variables are presented in Table 3. 


\section{Hypothesis Testing}

To test our mediation hypothesis, we followed the principles outlined by Baron and Kenny (1986) and used in Study 1. From Table 3 it can be seen that: (1) participants' perceptions of their workgroup's procedural fairness was significantly related to the dependent variable of OCBI, (2) workgroup procedural fairness was significantly related to the hypothesized mediating variable of participants' workgroup commitment, and (3) workgroup commitment was significantly related to OCBI. Given this pattern of results, we then regressed OCBI on workgroup procedural fairness and workgroup commitment simultaneously, finding that the effect of workgroup procedural fairness became trivial $(\beta=.05, p>.25)$, whereas the effect of workgroup commitment remained highly significant $(\beta=.17, p<.001)$. Furthermore, the results of a Sobel test showed that the relationship between workgroup procedural fairness and OCBI was significantly reduced when workgroup commitment was controlled, relative to when it was not, $z=3.48, p<.001$. These results show that commitment to the workgroup fully mediated the relationship between workgroup procedural fairness and OCBI.

\section{General Discussion}

In summary, all hypotheses received support. In Study 1 we found that OCBO was more strongly predicted by commitment to the organization than by workgroup commitment, whereas OCBI was more strongly predicted by workgroup commitment than by organizational commitment. In addition, organizational commitment fully mediated the relationship between organizational procedural justice and OCBO. Moreover, in Study 2, we found that commitment to the workgroup fully mediated the relationship between workgroup procedural fairness and OCBI.

\section{Theoretical Implications}

Differentiating Types of Citizenship According to the Target. LePine et al.'s (2002) meta- 
analysis concluded that additional research and theory were needed to assess whether or not differentiating between types of citizenship behavior as a function of the intended target can provide a meaningful way to clarify the nomological network of the citizenship construct. In response to this call, our research finds that employees indeed differentiate between OCBO and OCBI, in that these two types of citizenship behavior had unique predictors. In particular, our findings support the logic of the target similarity model (Lavelle et al., in press), suggesting the importance of taking a multifoci approach to both citizenship behavior and its predictors. That is, rather than positing that procedural fairness influences commitment, which in turn influences $\mathrm{OCB}$, we need to examine how certain sources of procedural fairness influence commitment to certain targets, which in turn influence citizenship behavior directed toward certain targets. Moreover, whereas previous reviews have suggested that the corrected meta-analytic correlation between commitment and OCB (target unspecified) is .25 (Riketta, 2002), in Study 1, we found that the correlation between organizational commitment and OCBO increased in magnitude to .43 (when we controlled for both commitment to the workgroup and procedural fairness).

Recent studies also lent some support to a target similarity effect, which showed that relationships between employee commitment and OCB (Becker \& Kernan, 2003), and between procedural fairness and OCB (Rupp \& Cropanzano, 2002) were generally stronger when the target was similar rather than different. The present findings provide further evidence of a target similarity effect but also extend the earlier results in a number of important respects. For instance, both studies are the first to show that commitment mediates the relationship between procedural fairness and citizenship behavior. In Study 1, organizational commitment (but not workgroup commitment) mediated the relationship between organizational procedural fairness and OCBO, whereas Study 2 showed that workgroup commitment mediated the relationship between workgroup procedural 
fairness and OCBI. Second, in both studies, target similarity effects emerged when the "I" in OCBI consisted of workgroup members, extending the findings of previous studies (Becker \& Kernan, 2003; Rupp \& Cropanzano, 2002), in which the individuals referred to supervisors. Third, the present findings go beyond previous empirical research that has shown the value of applying a multifoci perspective to the constructs of procedural fairness, commitment, and OCB. Whereas previous research has provided evidence of a target similarity effect when two of the three constructs are considered at a time (i.e., commitment and $\mathrm{OCB}$, justice and $\mathrm{OCB}$ ), the present studies illustrate show that the target similarity effect holds when all three constructs are considered simultaneously, in particular, that commitment mediates the relationship between procedural fairness and OCB.

Survivors' Reactions to Layoffs. The results of Study 1 also contribute to theory and research on survivors' reactions to job layoffs. Although numerous studies have delineated factors that may account for the variability in survivors' reactions (e.g., Brockner, 1994), the present research is the first to examine some of the determinants of a dependent variable of particular importance in a downsizing context: OCB. Whether layoffs have their intended effects on organizational performance is likely to depend upon the extent to which the employees who remain are willing to go beyond the call of duty. The present findings show that: (1) survivors' OCB depends upon their level of commitment, and moreover, in a target-specific way, and (2) the organization's procedural fairness in implementing the layoffs predicts OCBO, mediated by survivors' commitment to the organization.

Future Research. An additional area for future research would be to identify boundary conditions of the target similarity effect. The theory of reasoned action suggests that maximal prediction of behavior by attitude occurs when the attitude corresponds to behavior in terms of 
context, time, and target. Whereas we focused on the target dimension, the magnitude of the relationships between constructs may also depend upon context and time. For example, Price, Lavelle, Henley, Cochiarria, and Buchanan (2006) examined a multiple-stage decision making process in which different authorities made successive recommendations to an ultimate decisionmaking party. In a multiple-stage process the ultimate decision is affected by the procedures used by the various parties at each stage of the process. Price et al. found that the intention to volunteer for future committee work (a form of OCB) was jointly influenced by the procedures used by the participant's committee chair and by the procedures used by the authority at the subsequent stage of decision making. That is, the positive relationship between the committee chair's fairness and participants' future willingness to serve on the committee (a target similarity effect) was weakened when the authority at the subsequent stage of decision making exhibited lower procedural fairness.

To cite another example of a boundary condition on a target similarity effect, suppose that employees' religious beliefs led them to believe that it was particularly important to do extra for others around the time of the holidays. In that case, a better predictor of whether they will perform OCB towards a particular target is not the target, but rather the time of year, such that they may be more likely to do OCB around the holidays than at other times. In this instance, the "time similarity effect" may outweigh or otherwise reduce the target similarity effect.

\section{Limitations}

The present research also has a number of shortcomings. In calling attention to them, we are simultaneously suggesting additional avenues for future research. First, given the cross-sectional nature of the research designs in both studies, the causal impact of the independent variables on OCB is uncertain. Relatedly, the dependent variable in Study 1 asked participants to indicate 
whether and how their OCB had changed, relative to before the layoffs. It would have been more desirable if OCB had been measured both before and after the layoffs, which would have enabled us to compute the change in OCB directly, rather than leaving it to participants' subjective estimates. In a previous study examining the effect of procedural fairness, Brockner, Grover, Reed, DeWitt, and O’Malley (1987) conducted an internally valid laboratory experiment in which participants' reactions were measured both before and after the layoffs. (The dependent variable in that study was work motivation, rather than OCB.) The results of the earlier study were conceptually analogous to those found here, in that survivors responded more positively when procedural fairness was relatively high. In other words, the results of Study 1 do not appear to be an artifact of the crosssectional nature of the research design, or of the fact that the dependent variable consisted of participants' self-reports of how their OCB had changed, relative to before the layoffs.

Furthermore, even with the use of self-reported change measures, we still found evidence of target similarity effects. That is, change in commitment to the organization was a better predictor of change in citizenship toward the organization than was change in commitment to the workgroup, whereas change in commitment to the workgroup was a better predictor of change in citizenship toward co-workers than was change in commitment to the organization. In addition, the measure of OCB in Study 2 did not require raters to indicate how their OCB had changed over time, and still yielded mediation results conceptually analogous to those found in Study 1.

Second, although the meta-analytic results presented earlier (e.g., Riketta, 2002) indicate that the relationships between commitment and OCB in Study 1 were unlikely to be influenced by the use of self-reports to measure OCB, it could still be argued that the findings of Study 1 were tainted by common methods bias. Although this concern cannot be eliminated entirely, the confirmatory factor analysis in Study 1 suggested that the constructs in Study 1 were meaningfully 
separable. Also, the common methods alternative explanation is hard-pressed to explain why employees' commitment was more strongly related to OCB when the target was similar rather than different. Furthermore, note that common methods was not present in Study 2 (in that the measure of citizenship was based on peers' ratings rather than self-reports), and yet we still found evidence consistent with the target similarity effect.

Third, although we obtained evidence that the respondents in Study 1 were demographically similar to the overall organization, concerns of response bias may still be raised. For example, if completing a survey is considered to be an OCB, it could be argued that respondents in Study 1 are generally more likely to engage in OCB than non-respondents. However, this type of response bias may have led to a restricted range on the measure of OCB, thereby making it less likely to find support for the Study 1 hypotheses, in which OCB served as the dependent variable. Moreover, response bias was much less likely to be present in Study 2, and yet we still found support for the predicted mediating effect of commitment to the workgroup on the relationship between the workgroup's procedural fairness and citizenship directed towards the workgroup.

Fourth, concerns may arise due to the use of student project teams in Study 2. Note however, that the majority of student participants (80\%) were employed at least part-time and thus were likely to have considerable experience working in organizational teams. Moreover, it is also reassuring that the heretofore untested hypothesis that commitment would mediate the relationship between procedural fairness and OCB was replicated in our research across two very different settings (an organizational layoff and a student group project). In both instances, target-specific commitment mediated the relationship between procedural fairness and citizenship behavior.

Fifth, the research contexts made it implausible for us to examine all target-specific measures of procedural fairness, commitment, and citizenship behavior. For example, workgroup 
procedural fairness was not particularly meaningful in Study 1, and organizational procedural fairness was not especially relevant in Study 2. Whereas it is reassuring that conceptually analogous results emerged across studies, future research should be extended to different contexts in which all target-specific constructs may be relevant.

Finally, whereas the measures of citizenship behavior in Study 1 were used because they were based on previously validated scales, and because they clearly distinguished between intended beneficiaries (i.e., the organization and the workgroup), the scales consisted of a relatively small number of items. Thus, future research may consider using additional items to measure citizenship, and thereby broaden the generality of the present findings. For that matter, it would be worth examining the present findings with more expansive measures of the other main constructs (procedural fairness and commitment), in order to verify that the present results are not an artifact of or limited to the particular items used to assess the various constructs. Once again, it is worth emphasizing that although the measures of citizenship toward the organization and citizenship toward co-workers consisted of a small number of items, they were differentially related to organizational and workgroup commitment as a function of target similarity.

\section{Practical Implications}

Given the potential significance of OCB in general and following layoffs in particular, the present findings usefully identify factors that make citizenship behavior more versus less likely to occur. Moreover, the multifoci perspective and resulting target similarity effects serve to remind managers that the various forms of employee commitment are not equivalent in their consequences. If managers' aim is to promote organizationally-directed citizenship, then they need to foster organizational commitment. If their aim is to promote citizenship toward individuals, then they need to foster commitment to those particular targets. 
How might commitment to a particular target be built? One determining factor suggested by the present findings is procedural fairness. More specifically, employee commitment to a particular target depends upon the procedural fairness exhibited by that target. More generally, considering the favorable reactions elicited by both organizational and workgroup procedural fairness, it is reassuring to know that it is possible to train managers in how to be more procedurally fair when planning and implementing decisions (e.g., Skarlicki \& Latham, 1996). 


\section{References}

Ajzen, I., \& Fishbein, M. (1977). Attitude-behavior relations. A theoretical analysis and review of empirical research. Psychological Bulletin, 84: 888-918.

Ajzen, I. \& Fishbein, M. (1980). Understanding attitudes and predicting social behavior. Englewood Cliffs, NJ: Prentice-Hall, Inc.

Allen, N. J., \& Meyer, J. P. (1990). The measurement and antecedents of affective, continuance, and normative commitment to the organization. Journal of Occupational Psychology, 63: $1-18$.

Andersen, J. C., \& Gerbing, D. W. (1988). Structural equation modeling in practice: A review and recommended two-step approach. Psychological Bulletin, 103: 411-423.

Baron, R. M., \& Kenny, D. A. (1986). The moderator-mediator variable distinction in social psychological research: Conceptual, strategic, and statistical considerations. Journal of Personality and Social Psychology, 51: 1173-1182.

Becker, T. E. (1992). Foci and bases of commitment: Are they distinctions worth making? Academy of Management Journal, 35: 232-244.

Becker, T. E., \& Kernan, M. (2003). Matching commitment to supervisors and organizations to inrole and extra-role performance. Human Performance, 16: 327-348.

Bennett, R. J., \& Robinson, S. L. (2000). Development of a measure of workplace deviance. Journal of Applied Psychology, 85: 349-360.

Bishop, J. W., \& Scott, K. D. (2000). An examination of organizational and team commitment in a self-directed team environment. Journal of Applied Psychology, 85: 439-450.

Blau, P. M. (1964). Exchange and power in social life. New York: John Wiley \& Sons. Blader, S. L., \& Tyler, T. R. (2003). A four-component model of procedural justice: Defining the 
meaning of a "fair" process. Personality and Social Psychology Bulletin, 29: 747-758.

Brockner, J. (1994). Perceived fairness and survivors reactions to layoffs, or how downsizing organizations can do well by doing good. Social Justice Research, 7: 345-363.

Brockner, J., Grover, S., Reed, T., DeWitt, R., \& O’Malley, M. (1987). Survivors' reactions to layoffs: We get by with a little help from our friends. Administrative Science Quarterly, 32: 526-541.

Brockner, J., Tyler, T. R., \& Cooper-Schneider, R. (1992). The influence of prior commitment to an institution on reactions to perceived unfairness: The higher they are, the harder they fall. Administrative Science Quarterly, 37: 241-261.

Cascio, W. F. (1993). Downsizing: What do we know? What have we learned? Academy of Management Executive, 7: 95-105.

Cohen-Charash, Y., \& Spector, P. E. (2001). The role of justice in organizations: A metaanalysis. Organizational Behavior and Human Decision Processes, 86: 278-321.

Colquitt, J. A., Conlon, D. E., Wesson, M. J., Porter, C. O., \& Ng, K. Y. (2001). Justice at the millennium: A meta-analytic review of 25 years of organizational justice research. Journal of Applied Psychology, 86: 425-445.

Coyle-Shapiro, J. A-M., \& Morrow, P.C. (2006). Organizational and client commitment among contracted employees. Journal of Vocational Behavior, 68: 416-431.

Cropanzano, R., Byrne, Z. S., Bobocel, D. R., \& Rupp, D. E. 2001. Moral virtues, fairness heuristics, social entities, and other denizens of organizational justice. Journal of Vocational Behavior, 58: 164-209.

Cropanzano, R., \& Mitchell, M. (2005). Social exchange theory: An interdisciplinary review. Journal of Management, 31: 874-900. 
Cropanzano, R., \& Rupp, D. E. (In press). Social exchange theory and organizational justice: Job performance, citizenship behaviors, multiple foci, and a historical integration of two literatures. Research in Social Issues in Management.

Ehrhart, M. G. (2004). Leadership and procedural justice climate as antecedents of unit-level organizational citizenship behavior. Personnel Psychology, 57: 61-94.

Eisenberger, R., Huntington, R., Hutchison, S., \& Sowa, D. (1986). Perceived organizational support. Journal of Applied Psychology, 71: 500-507.

Fishbein, M., \& Ajzen, I. (1975). Belief, attitude, intention, and behavior. Reading, MA.: Addison-Wesley.

Folger, R., \& Cropanzano, R. (1998). Organizational justice and human resource management. Thousand Oaks, CA: Sage Publications.

Grandey, A. (2003). When "the show must go on": Surface acting and deep acting as determinants of emotional exhaustion and peer-rated service delivery. Academy of Management Journal, 46: 86-96.

Greenberg, J. (1993). Stealing in the name of justice: Informational and interpersonal moderators of theft reactions to underpayment inequity. Organizational Behavior and Human Decision Processes, 54: 81-103.

Konovsky, M. A., \& Pugh, S. D. (1994). Citizenship behavior and social exchange. Academy of Management Journal, 37: 656-669.

Lavelle, J.J., Rupp, D.E., \& Brockner, J. (In press). Taking a multifoci approach to the study of justice, social exchange, and organizational citizenship behavior: The target similarity model. Journal of Management.

Lee, K., \& Allen, N. J. (2002). Organizational citizenship behavior and workplace deviance: The 
role of affect and cognitions. Journal of Applied Psychology, 87: 131-142.

LePine, J. A., Erez, A., \& Johnson, D. E. (2002). The nature and dimensionality of organizational citizenship behavior: A critical review and meta-analysis. Journal of Applied Psychology, 87: 52-65.

Leventhal, G. S., Karuza, J., \& Fry, W. R. (1980). Beyond fairness: A theory of allocation preferences. In G. Mikula (Ed.), Justice and social interaction, 167-218. New York: Springer-Verlag.

Liden, R. C., Wayne, S. J., Kraimer, M. L., Sparrowe, R. T. 2003. The dual commitments of contingent workers: An examination of contingents' commitment to the agency and the organization. Journal of Organizational Behavior, 24: 609-625.

Lind, E. A., \& Tyler, T. R. (1988). The social psychology of procedural justice. New York: Plenum. Mathieu, J. E., \& Zajac, D. M. (1990). A review and meta-analysis of the antecedents, correlates, and consequences of organizational commitment. Psychological Bulletin, 108: 171-194.

McNeely, B. L., \& Meglino, B. M. (1994). The role of dispositional and situational antecedents in prosocial organizational behavior: An examination of the intended beneficiaries of prosocial organizational behavior. Journal of Applied Psychology, 76: 845-855.

Moorman, R. H. (1991). Relationship between organizational justice and organizational citizenship behaviors: Do fairness perceptions influence employee citizenship? Journal of Applied Psychology, 76: 845-855.

Moorman, R.H., Niehoff, B.P., \& Organ, D.W. (1993). Treating employees fairly and organizational citizenship behavior: Sorting the effects of organizational commitment, job satisfaction, and procedural justice. Employee Responsibilities and Rights Journal, 6, 209225. 
Morrison, E. W. (1994). Role definitions and organizational citizenship behavior: The importance of the employee's perspective. Academy of Management Journal, 37: 1543-1567.

Mowday, R. T., Porter, L. W., \& Steers, R. M. (1982). Employee-organization linkages: The psychology of commitment, absenteeism, and turnover. New York: Academic Press.

O’Malley, M. (2000). Creating commitment: How to attract and retain talented employees by building relationships that last. New York: John Wiley \& Sons.

O’Reilly, C., \& Chatman, J. (1986). Organizational commitment and psychological attachment: The effects of compliance, identification, and internalization on prosocial behavior. Journal of Applied Psychology, 71: 492-499.

Organ, D. W. (1988). Organizational citizenship behavior: The good soldier syndrome. Lexington, MA: Lexington Books.

Organ, D. W. (1997). Organizational citizenship behavior: It's construct clean-up time. Human Performance, 10: 85-97.

Organ, D. W., \& Ryan, K. 1995. A meta-analytic review of attitudinal and dispositional predictors of organizational citizenship behavior. Personnel Psychology, 48: 775-802.

Podsakoff, P. M., MacKenzie, S. B., Lee, J., \& Podsakoff, N. P. (2003). Common method biases in behavioral research: A critical review of the literature and recommended strategies. Journal of Applied Psychology, 88: 879-904.

Podsakoff, P. M., MacKenzie, S. B., Moorman, R. H., \& Fetter, R. (1990). Transformational leader behaviors and their effects on followers' trust in leader, satisfaction, and organizational citizenship behaviors. Leadership Quarterly, 1: 107-142.

Price, K. H., Lavelle, J. J., Henley, A. B., Cocchiara, F., \& Buchanan, F. R. (2006). Judging the fairness of voice-based participation across multiple and interrelated stages of decision 
making. Organizational Behavior and Human Decision Processes, 99: 212-226.

Reichers, A. E. (1985). A review and reconceptualization of organizational commitment. Academy of Management Review, 10: 465-476.

Rhoades, L., Eisenberger, R., \& Armeli, S. 2001. Affective commitment to the organization: The contribution of perceived organizational support. Journal of Applied Psychology, 86: $825-836$

Riketta, M. (2002). Attitudinal organizational commitment and job performance: A metaanalysis. Journal of Organizational Behavior, 23: 257-266.

Rupp, D. E., \& Cropanzano, R. (2002). The mediating effects of social exchange relationships in predicting workplace outcomes from multifoci organizational justice. Organizational Behavior and Human Decision Processes, 89: 925-946.

Skarlicki, D. P., \& Latham, G. P. (1996). Increasing citizenship behavior within a labor union: A test of organizational justice theory. Journal of Applied Psychology, 81: 161-169.

Smith, C. A., Organ, D. W., \& Near, J. P. (1983). Organizational citizenship behavior: Its nature and antecedents. Journal of Applied Psychology, 68: 653-663.

Tyler, T. R., \& Lind, E. A. (1992). A relational model of authority in groups. In M. P. Zanna (Ed.), Advances in experimental social psychology, 25: 115-191. San Diego: Academic Press.

Van Dyne, L., Graham, J.W., \& Dienesch, R.M. (1994). Organizational citizenship behavior: Construct redefinition, measurement and validation. Academy of Management Journal, 37: 765-802.

Van Dyne, L., \& LePine, J. A. (1998). Helping and voice extra-role behavior: Evidence of construct and predictive validity. Academy of Management Journal, 37: 765-802. 
Viswesvaran, C., \& Ones, D. S. (2002). Examining the construct of organizational justice: A meta-analytic evaluation of relations with work attitudes and behaviors. Journal of Business Ethics, 38: 193-203.

Weigel, R. H. \& Newman, L. S. (1976). Increasing attitude-behavior correspondence by broadening the scope of the behavioral measure. Journal of Personality and Social Psychology, 33: 793802.

Williams, L. J., \& Anderson, S. E. (1991). Job satisfaction and organizational commitment as predictors of organizational citizenship and in-role behaviors. Journal of Management, 17: 601-617. 


\section{Footnotes}

1. We do not mean to suggest that the fairness exhibited by fellow workgroup members is entirely irrelevant to the survivors of an organizational downsizing. For example, it could be argued that the interactional fairness exhibited by workgroup members (towards either the employees who lost their jobs or to the survivors themselves) may have an impact on the reactions of layoff survivors. In fact, we collected a three-item measure designed to assess interactional fairness (a sample item is: "Members of my workgroup were concerned about the needs and well-being of those laid-off'). However, there was essentially no variance in this measure $(90 \%$ of the responses were in the 6-7 range on a 7-point scale, in which the endpoints were "strongly disagree" (1) and "strongly agree" (7)), hence, its impact could not be tested meaningfully in Study 1. The procedural fairness exhibited by fellow workgroup members in Study 2 showed a reasonable degree of variance, thereby better allowing us to examine its impact. 
Table 1

Means, Standard Deviations, Reliabilities, ${ }^{a}$ and Correlations among Study 1 Variables

\begin{tabular}{|c|c|c|c|c|c|c|c|}
\hline Variable & Mean & S.D. & 1 & 2 & 3 & 4 & 5 \\
\hline 1. $\mathrm{OCBO}$ & 5.25 & 1.97 & $(.87)$ & & & & \\
\hline 2. OCBI & 6.44 & 1.43 & $.34 * *$ & $(.97)$ & & & \\
\hline $\begin{array}{l}\text { 3. Commitment to } \\
\text { the organization }\end{array}$ & 4.69 & 1.75 & $.52 * *$ & $.22 *$ & $(.79)$ & & \\
\hline $\begin{array}{l}\text { 4. Commitment to } \\
\text { the workgroup }\end{array}$ & 6.32 & 1.72 & $.29 * *$ & $.35^{* *}$ & $.32 * *$ & $(.90)$ & \\
\hline $\begin{array}{l}\text { 5. Organizational } \\
\text { procedural fairness }\end{array}$ & 3.20 & 1.47 & $.26 * *$ & $.22 *$ & $.31 * *$ & .10 & $(.92)$ \\
\hline
\end{tabular}

${ }^{a}$ Scale reliabilities appear in parentheses on the diagonal.

Note: OCBO denotes citizenship behavior toward the organization whereas OCBI denotes citizenship toward individual co-workers. Organizational procedural fairness was measured with a 7-point scale. All other variables were measured using 11-point scales.

$\begin{array}{ll}* & \mathrm{p} \leq .05 \\ * * & \mathrm{p} \leq .01\end{array}$ 
Table 2

Results of Regression Analyses Predicting OCBO and OCBI for Study $1^{a}$

Independent Variables

Dependent Variables

$\underline{\mathrm{OCBO}} \quad \underline{\mathrm{OCBI}}$

Commitment to the organization

Commitment to the workgroup

Organizational procedural fairness

$.45^{* *} \quad .07$

$.14 \quad .31 * *$

$.10 \quad .16$

$\mathrm{R}^{2}$

$.30 * *$

$.16^{* *}$

${ }^{a}$ When these analyses were conducted controlling for age and organizational tenure, the results were highly similar to, and the conclusions drawn did not change from, those reported here.

Note: Standardized regression coefficients are reported.

$$
\begin{array}{r}
* \mathrm{p}<.05 \\
* * \mathrm{p}<.01
\end{array}
$$


A Multifoci Analysis 45

Table 3

Means, Standard Deviations, Reliabilities, ${ }^{a}$ and Correlations among Study 2 Variables

\begin{tabular}{lccccc}
\hline Variable & Mean & S.D. & 1 & 2 & 3 \\
\hline 1. OCBI & 5.71 & 1.00 & - & & \\
$\begin{array}{l}\text { 2. Workgroup commitment } \\
\begin{array}{l}\text { 3. Workgroup procedural } \\
\text { fairness }\end{array}\end{array}$ & 5.72 & 1.32 & $.20^{* *}$ & $(.96)$ & \\
& 5.95 & 1.07 & $.14^{* *}$ & $.52^{* *}$ & $(.97)$ \\
& & & & & \\
\end{tabular}

${ }^{\text {a }}$ Scale reliabilities appear in parentheses on the diagonal.

Note: OCBI denotes citizenship behavior toward individual co-workers. All variables were measured using 7-point scales.

$* * \mathrm{p} \leq .01$ 